\title{
HABILIDADES DOS RECÉM-FORMADOS EM CONTABILIDADE: ANÁLISE DA PERCEPÇÃO DOS PROFISSIONAIS DE RECRUTAMENTO
}

\author{
THE SKILLS OF RECENTLY GRADUATED ACCOUNTANTS: ANALYSIS OF THE \\ PERCEPTION OF RECRUITMENT PROFESSIONALS
}

\author{
Claudio de Souza Miranda ${ }^{1}$ \\ Universidade de São Paulo \\ csmiranda@usp.br
}

\author{
João Paulo Resende de Lima \\ Universidade de São Paulo \\ jprlima@usp.br
}

\author{
Thais Coelho de Souza \\ Universidade de São Paulo \\ thaiscoelhosouza@outlook.com
}

\begin{abstract}
RESUMO
Estudos recentes indicam maior necessidade de qualificação dos profissionais contábeis brasileiros, principalmente acerca de suas soft skills. Para que os profissionais em formação (estudantes de ciências contábeis) possam atingir as expectativas dos recrutadores, é necessário, primeiramente, identificar o perfil traçado por aqueles profissionais no preenchimento das vagas demandadas pelo mercado. Diante desse cenário, o presente estudo objetivou identificar as principais competências e habilidades requisitadas aos profissionais contábeis vis-à-vis aquelas encontradas pelos recrutadores em geral, por meio de uma websurvey com profissionais de recrutamento e gerentes de recursos humanos, visando obter o perfil esperado dos profissionais formados em Contabilidade. O presente estudo contribui para a discussão das habilidades e competências dos profissionais de contabilidade, bem como apresenta potencial reflexivo para os coordenadores de curso que desejam aumentar seu nível de empregabilidade e diálogo com profissionais de recrutamento e seleção.
\end{abstract}

Palavras-chave: Habilidades. Profissional Contábil. Formação Profissional.

\section{ABSTRACT}

Recent studies indicate a greater need for qualification of Brazilian accounting professionals, especially regarding their soft skills. So that professionals in training (accountancy students) can meet recruiters' expectations, it is first necessary to identify the professionals' profile in filling the market's vacancies. Given this scenario, the present study aimed to identify the main

\footnotetext{
${ }^{1}$ Avenida Bandeirantes, 3900, Monte Alegre -Ribeirão Preto - SP CEP 14040-905

* Versão anterior do trabalho apresentada no 3th UnB Conference on Accounting and Governance (2017).
} 
competencies and skills required from accounting professionals vis-à-vis those found by recruiters in general, through a web survey with recruiting professionals and human resources managers, to obtain the expected profile professionals trained in Accounting. The present study contributes to the discussion of the skills and competencies of accounting professionals. It presents reflective potential for course coordinators who wish to increase their employability and dialogue with recruitment and selection professionals.

Keywords: Skills. Accounting Professional. Professional Training.

\section{INTRODUÇÃO}

A contabilidade e as demais ciências sociais estão sempre em mudança para se adequarem às necessidades da sociedade, assim o profissional contábil - e das demais ciências sociais - deve estar sempre se atualizando para suprir estas necessidades (Iudícibus, Carvalho, \& Martins, 2005). Nesse sentido é notável que as mudanças na contabilidade têm possibilitado a oferta de novos serviços, consequentemente as exigências são alteradas, exigindo-se um profissional multidisciplinar que atua como líder e tomador de decisões (Picard, Durocher, \& Gendron, 2014).

Assim como no cenário internacional, no Brasil as habilidades do contador também passam por alterações - principalmente em decorrência da adoção das normas no padrão International Financial Reporting Standards (IFRS) e mais recentemente da indústria 4.0 (Marin, Lima, \& Nova, 2014; Tan \& Laswad, 2018; Douglas \& Gammie, 2019; Lima, Vendramin, \& Miranda, 2020). Dentre as novas exigências do profissional contábil destacamse as chamadas soft skills - também chamadas de habilidades genéricas ou não técnicas (Tan \& Laswad, 2018), como a inteligência emocional (Coady, Byrne, \& Casey, 2018), capacidade de trabalhar em grupo e desenvolver relacionamentos interpessoais (Tan \& Laswad, 2018), além da capacidade de se comunicar adequadamente (Douglas \& Gammie, 2019) e de raciocínio crítico (Cloete, 2018).

No contexto educacional brasileiro, as competências e habilidades dos profissionais contábeis são instituídas pela Resolução CNE/CES 10/2004, sendo tais competências e habilidades indicadas nos projetos pedagógicos das instituições brasileiras (Kruger et al., 2013). A discussão acerca das competências esperadas do profissional contábil perpassa não apenas o mercado de trabalho, mas também às Instituições de Ensino Superior (IES), visto que um dos indicadores utilizados para sinalizar a qualidade e aceitabilidade do curso pelo mercado de trabalho é a empregabilidade (Lim et al., 2019). Dessa maneira, deve existir um grau de alinhamento entre o que as IES acreditam ser importantes para desenvolver em seus estudantes e o quê o mercado acredita ser relevante na formação dos profissionais de contabilidade (Lim et al., 2016; Thomsom, 2017). Diante desse contexto o presente trabalho tem o objetivo de analisar a percepção dos profissionais de recrutamento e seleção acerca das habilidades mais importantes do profissional contábil recém-formado. $O$ presente trabalho justifica-se na necessidade de refletir sobre o profissional que tem sido formado e o profissional contábil que o mercado deseja, visando alinhar as expectativas entre as habilidades e competências da formação com as práticas de atuação, requisitadas pelas organizações.

Para atingir o objetivo proposto foi realizada uma pesquisa pautada na estratégia de websurvey com uma amostra de 47 recrutadores de todo o país, sendo $51,1 \%$ da amostra formada por profissionais de recrutamento. Os resultados apontam que as habilidades mais esperadas pelos respondentes são: comprometimento, habilidade com planilhas eletrônicas (Excel), trabalho em equipe, resolução de problemas e pró-atividade. Observa-se ainda a existência de um gap entre a expectativa de algumas habilidades por parte dos respondentes e seu desenvolvimento nos candidatos recém-formados dos cursos de contabilidade. 
O presente trabalho contribui teoricamente para a literatura que discute a relação entre mercado e as IES, ao analisar as principais expectativas do mercado e seu nível de satisfação com a formação dos profissionais recém-formados. Além disso, a pesquisa contribui teoricamente para a discussão das habilidades dos profissionais de contabilidade, bem como apresenta potencial reflexivo para os coordenadores de curso que desejam aumentar o nível de empregabilidade e diálogo com profissionais de recrutamento e seleção.

Acerca de sua estrutura, o estudo encontra-se dividido em cinco seções, tendo início nessa introdução. Em seguida são apresentadas as discussões acerca da conceituação e diferenciação entre habilidade e competência; o histórico das habilidades do profissional de contabilidade e os estudos anteriores. Na terceira sessão apresenta-se o percurso metodológico percorrido para a realização da pesquisa. Por fim, são apresentados e discutidos os resultados da pesquisa e as considerações finais.

\section{REFERENCIAL TEÓRICO}

Diante do aumento das complexidades impostas pelo desenvolvimento social, econômico e tecnológico a cada dia exige-se mais dos profissionais das mais diversas áreas (Vendramin \& Araujo, 2020). A partir dessa complexidade é que se define um profissional segundo Le Boterf (2003), que seja capaz de lidar com a complexidade de sua área de atuação e que para ser reconhecido como profissional o indivíduo deve saber agir com competência.

A partir dessa colocação de Le Boterf (2003) percebe-se a importância da discussão acerca das competências: são elas que caracterizam um profissional. Apesar dessa importância, o termo competência tem sido analisado por diversas áreas na literatura que apesar do esforço e das diversas discussões ainda não apresenta um consenso quanto sua definição (Cardoso, Riccio, \& Albuquerque, 2009).

Le Boterf (2003) posiciona a competência na sobreposição de três eixos: a pessoa e sua história pessoal e de socialização, a formação educacional e sua experiência profissional. $\mathrm{O}$ autor ainda destaca que a noção de competência só ganhou importância a partir da década de 1980 para substituir a discussão acerca de "qualificação". Já Fleury e Fleury (2001) indicam que a compreensão do conceito dever ser observada a partir de três dimensões: (i) a competência do indivíduo; (ii) às organizações (seu core competence); e (iii) a dos países - focando em seus sistemas educacionais e desenvolvimento de competências.

No âmbito das competências profissionais Deluiz (2001) afirma que esta é a capacidade de mobilizar e articular conhecimentos, habilidades e atitudes para resolver problemas e situações de imprevisibilidade em dado contexto da profissão. Já Desprebiteris (2001), define a competência como um "conjunto identificável de conhecimentos (saberes), práticas/habilidades (saber fazer) e atitudes (saber ser) que mobilizados podem levar a um desempenho satisfatório". As competências podem ainda ser definidas como o produto da união dos Conhecimentos, Atitudes e Habilidades (Marin, Lima, \& Nova, 2014).

No presente trabalho adota-se habilidade como proposto por Perrenoud (1999) que é expressa pela capacidade de mobilizar conhecimentos para resolver uma situação problema da vida real, ou seja, "habilidade é uma série de procedimentos mentais que o indivíduo aciona para resolver uma situação real, onde ele precise tomar uma decisão" (Silva \& Felicetti, 2014). Considerando a definição adotada percebe-se que as habilidades exigidas de determinada profissão são contextualizadas historicamente e socialmente. Dessa forma, as habilidades exigidas do profissional contábil têm mudado de acordo com as necessidades da profissão que se alteram de acordo com as demandas da sociedade, especialmente da área de Ciências Sociais e Ciências Sociais Aplicadas (Iudícibus, Carvalho, \& Martins, 2005), assim, cabe às instituições de ensino estarem atentas às necessidades do mercado de trabalho. 


\subsection{As habilidades do contador: panorama histórico}

Para alguns autores, como Lopes de Sá (2009), a contabilidade teria surgido a partir da necessidade social do ser humano de proteção dos seus bens, da perpetuação da espécie e da interpretação dos fatos ocorridos. Assim, desde o surgimento das civilizações, o papel do contador sempre esteve presente na história (Mattessich, 1989). Segundo historiadores (Brown, 2004), os primeiros sinais, ainda que primitivos, dos registros contábeis surgiram por volta de 8.000 a.C.; o homem utilizava instrumentos rudimentares para registrar e controlar seu patrimônio, como tábuas de barro cozido, placas de madeira ou pedras.

Já no século XV os mercadores venezianos utilizavam o sistema de partidas dobradas para apurar o resultado de suas vendas, já a partir dos séculos XVII e XVIII com a Revolução Industrial surgiu a necessidade de um sistema de custos para a compreensão dos recursos que estavam sendo utilizados na produção das fábricas (Martin, 2002). Já por ocasião do descobrimento apareceram os primeiros registros contábeis no Brasil, como visto, fruto dos empreendimentos navais, numa época em que a contabilidade se desenvolvia à medida que o mercantilismo se expandia país a fora (Rodrigues \& Sangster, 2013; Russell-Wood, 2002).

Desse movimento, surgiu a primeira iniciativa em institucionalizar a formação do profissional contábil, a partir da proposta do governador do Estado de Grão-Pará e Maranhão, Francisco Xavier de Mendonça Furtado, em 1754, para criação de uma Aula de Comércio (a palavra aula era utilizada na época para referir-se à escola superior ou faculdade), sob a supervisão da Junta de Comércio de Lisboa, sendo aprovada pelo Decreto de 12 de dezembro de 1756 (Ericeira, 2003). Os licenciados nesse curso eram os guarda-livros, denominação utilizada na época para referir-se aos contadores, termo que foi utilizado até os idos de 1970. Através do Decreto Imperial $n^{\circ} .4 .475$ de 1870, a profissão de guarda-livros fora, então, regulamentada, exigindo- se, para sua atuação, apenas a formação em curso de comércio. Todavia, estudos como os de Peleias et al. (2007) e Peleias e Bacci (2004) indicam que, já nessa época, tratava-se da profissão conforme demanda multidisciplinar: exigia-se do guarda-livros conhecimentos da língua portuguesa e francesa, além de caligrafia perfeita, com a introdução dos equipamentos datilográficos, a habilidade de operá-los acabaria por substituir a demanda pela caligrafia.

No início do século XX, foram criados o Instituto Brasileiro de Contadores Fiscais, a Associação dos Contadores de São Paulo e o Instituto Brasileiro de Contabilidade no Rio de Janeiro, considerados os primeiros órgãos de classe a representar a profissão. Em 1924, essas entidades se organizaram no $1^{\circ}$ Congresso Brasileiro de Contabilidade, quando, então, ganharam corpo as campanhas para a regulamentação da profissão e reforma do ensino contábil no país (De Rocchi, 2007). Com a criação do primeiro Conselho, em 1927, passou-se a exigir o registro dos novos profissionais habilitados, no que, posteriormente, viria a se tornar o Conselhos Federal e Regional de Contabilidade, ainda que, nesse momento, sem grandes modificações no que tange à formação desses profissionais (Rodrigues, Schmidt, \& Santos, 2012).

A expansão da carreira do contador, impulsionada pelo desenvolvimento econômico, resultou também na demanda de capacitação, ainda que durante muitos anos a formação e a prática do ensino contábil não tenha se afastado muito das exigências curriculares e de mercado verificadas nos séculos XIX e XX (Peleias et al., 2007). Já no século XXI, o processo de globalização introduziu novas demandas na atuação dos profissionais da contabilidade, notadamente a adoção de um modelo contábil mais uniforme, que facilitasse o intercâmbio de informações que acompanham as transações internacionais envolvendo mercadorias, produtos e serviços: as chamadas normas internacionais de contabilidade (Jackling, Howieson, \& Natoli, 2012; Picard, Durocher, \& Gendron, 2014).

Considerando o fato de o ensino ser uma atividade que depende do contexto e histórico e social, faz-se necessário entender melhor a evolução do ensino contábil no Brasil. Nesse 
sentido, Silva (2015) analisou o processo de institucionalização do ensino contábil no Brasil e em Portugal no período de 1940 a 1985. A autora destaca o papel desempenhado pela Faculdade de Economia, Administração e Contabilidade da Universidade de São Paulo (FEA/USP) no Brasil. Além disso, a autora destaca a influência do modelo estadunidense a partir de 1970, sendo este visto principalmente no modo de ensinar Contabilidade Introdutória "que resultou na publicação de livro didático, ao qual se atribui considerável contribuição à metodologia de ensino praticada a partir de 1970, decorre da leitura e do uso de meterial utilizado naquele país" (p. 108).

Acerca das competências profissionais contábeis no século XX, Davidson (1994) analisou quais as diferenças entre estudantes que foram selecionados em processos seletivos e os que não foram, dentre as variáveis analisadas a única que apresentou significância estatística foi a média das disciplinas do candidato. Já Cook e Finch (1994) realizaram um levantamento bibliométrico para identificar as características mais importantes de profissionais contábeis recém-formados. Os resultados deste levantamento apontam que a formação do candidato, experiência profissional anterior e potencial de treinamento são os atributos mais importantes para os recrutadores. Schmutte (1998) realizaram uma survey com 122 alunos e 66 profissionais de seleção e recrutamento e posteriormente realizaram uma análise fatorial na qual o fator com maior carga foi o de habilidades interpessoais.

Já no século XXI, uma das principais mudanças da contabilidade, que impactou tanto a profissão quanto o ensino contábil foi a adoção do padrão contábil IFRS. Os impactos da adoção do padrão IFRS são diversos, contudo, estudos destacam o fato do sistema IFRS ser baseado em princípios e não em normas (Jackling, Howieson, \& Natoli, 2012), assim "a educação contábil terá de mudar e passar a dar menos ênfase na memorização de regras e mais ênfase na compreensão, principalmente, do arcabouço teórico" (Pereira, Niyama, \& Freire, 2012, p. 5).

Dado que a adoção do padrão IFRS exige uma formação baseada em princípios a atuação do contador passou a depender cada vez mais de novas habilidades como pensamento crítico e capacidade de tomada de decisões (Jackling, Howieson, \& Natoli, 2012). Avelino et al. (2010) afirmam que se de um lado a adesão das IFRS elevou o papel do profissional da contabilidade de outro, passou a exigir dos profissionais da área uma formação ainda mais abrangente e conectada com as necessidades das firmas num ambiente globalizado, dessa forma pode-se afirmam que o profissional contábil se tornou indispensável para as organizações e na sociedade (Cotrin, Santos, \& Zotte Júnior, 2012).

No que diz respeito a preferência de sexo para determinadas vagas na área contábil Hardin, Reding e Stocks (2002) demonstram que em situações hipotéticas de contratação não há diferenças ou preferência por determinado sexo. Wilder e Stock (2004) analisaram se os estudantes de contabilidade são mais procurados para cargos de gerência que os demais alunos da área de business e se um diploma de MBA também influenciaria suas chances de colocação no mercado de trabalho. Os resultados apontam que os candidatos com diploma em contabilidade são preferíveis para esses cargos na visão dos recrutadores.

Ibrahim e Angelidis (2009) analisaram quais as habilidades mais importantes para a colocação de um profissional contábil recém-formado na percepção 335 profissionais contábeis já empregados com tempo médio de 15 anos de experiência profissional. Entre as habilidades elencadas pelos respondentes as mais importantes foi o conhecimento técnico contábil, habilidades relacionadas à comunicação e habilidades interpessoais.

Em termos de Brasil, a Resolução CNE/CES 10/2004 institui as diretrizes curriculares nacionais para o curso de Ciências Contábeis. Nessa resolução, no artigo $4^{\circ}$ são apresentadas as competências e habilidades que devem ser desenvolvidas ao decorrer do curso de bacharelado em Ciências Contábeis, sendo tais competências e habilidades: 
I - utilizar adequadamente a terminologia e a linguagem das Ciências Contábeis e Atuariais;

II - demonstrar visão sistêmica e interdisciplinar da atividade contábil;

III - elaborar pareceres e relatórios que contribuam para o desempenho eficiente e eficaz de seus usuários, quaisquer que sejam os modelos organizacionais;

IV - aplicar adequadamente a legislação inerente às funções contábeis;

$\mathrm{V}$ - desenvolver, com motivação e através de permanente articulação, a liderança entre equipes multidisciplinares para a captação de insumos necessários aos controles técnicos, à geração e disseminação de informações contábeis, com reconhecido nível de precisão;

VI - exercer suas responsabilidades com o expressivo domínio das funções contábeis, incluindo noções de atividades atuariais e de quantificações de informações financeiras, patrimoniais e governamentais, que viabilizem aos agentes econômicos e aos administradores de qualquer segmento produtivo ou institucional o pleno cumprimento de seus encargos quanto ao gerenciamento, aos controles e à prestação de contas de sua gestão perante à sociedade, gerando também informações para a tomada de decisão, organização de atitudes e construção de valores orientados para a cidadania;

VII - desenvolver, analisar e implantar sistemas de informação contábil e de controle gerencial, revelando capacidade crítico analítica para avaliar as implicações organizacionais com a tecnologia da informação;

VIII - exercer com ética e proficiência as atribuições e prerrogativas que lhe são prescritas através da legislação específica, revelando domínios adequados aos diferentes modelos organizacionais.

Com base na resolução, observa-se que durante a graduação espera-se $o$ desenvolvimento de competências e habilidades relacionadas aos conhecimentos técnicos (hard skills) e competências e habilidades profissionais ( soft skill). Nesse sentido observam-se alguns estudos sobre as habilidades esperadas dos profissionais contábeis, tanto em termos técnicos (hard skill) como as habilidades profissionais (soft skill), tanto sob a ótica do mercado, quanto o da academia. Como exemplo, o trabalho de Meurer e Voese (2020) analisa o perfil requerido pelo mercado de trabalho, em vagas de emprego, para profissionais contábeis da área de custos. O estudo demonstra anseios técnicos do mercado como a necessidade de profissionais com forte formação em tecnologia e conhecimento em inglês, além de ter diversas habilidades sociais como comunicação, pensamento crítico, entre outros.

No trabalho de Kruger et al. (2013), observa-se na análise dos projetos político pedagógicos de curso de contabilidade no sul do Brasil, que quase todas as competências esperadas do contador indicadas nas diretrizes curriculares do curso (CNE/CES 10/2004) estão sendo indicadas. Cabe ressaltar, porém, a importância da atualização destas diretrizes, frente a rápida evolução que a profissão vem sofrendo.

\section{PROCEDIMENTOS METODOLÓGICOS}

Os métodos e técnicas de pesquisa devem se adequar ao problema proposto e às hipóteses levantadas e dependerão, entre outros, do objeto da pesquisa e dos recursos, da equipe e de eventuais outros elementos da investigação (Lakatos \& Marconi, 1999). Considerando que o objetivo desta pesquisa, optou-se pela adoção da pesquisa quantitativa (websurvey) para levantamento de dados por meio de questionários com recrutadores e gerentes de recursos humanos de todo o país.

O questionário é uma das técnicas de investigação da pesquisa survey, pela qual o pesquisador se vale de um instrumento escrito (ou digital, quando pesquisa websurvey) para coleta de dados, composto por uma série ordenada de perguntas que devem ser respondidas pelo entrevistado, sem a presença do entrevistador (Beuren, 2013). O objetivo de tal recurso metodológico é o conhecimento das opiniões dos entrevistados sobre determinado assunto, que, 
de outra forma, ou seriam inacessíveis, ou poderiam ser enviesadas em virtude da presença do entrevistador.

Por essa razão, uma primeira etapa da pesquisa consistiu na elaboração de questionário contendo as principais capacidades esperadas e encontradas nos profissionais contábeis, tomando-se por base as informações divulgadas em mídia especializada (Revista Exame S.A., Portal Administradores e websites de companhias especializadas em recrutamento, entre outros), além dos trabalhos apresentados no referencial teórico. O processo de validação do questionário foi realizado por meio de aplicação e discussão com estudante de pós-graduação.

Com base nas competências elencadas por meio do levantamento de literatura e mídia especializada o questionário foi organizado em quatro partes. A primeira e segunda parte visavam a descrição e caracterização do respondente e da organização em que o respondente trabalha. $\mathrm{Na}$ terceira seção - HABILIDADES - o respondente deveria responder, a partir de uma escala Likert de 4 pontos, qual o grau de importância de determinadas habilidades numa escala de "Irrelevante, Pouco Relevante, Relevante e Muito Relevante", e responder se nos últimos processos seletivos realizados por ele os candidatos com até dois anos de formados apresentaram essa habilidade de maneira adequada ou não. Por fim, na quarta seção - FORMAÇÃ̃O - os respondentes deveriam avaliar aspectos relacionados à formação do candidato na mesma escala que a seção anterior e indicar com que frequência esses aspectos eram encontrados em candidatos com até dois anos de formado para vagas na área contábil. Para esta questão as alternativas indicadas foram: Alta, Média, Baixa, Ausente/Rara.

Os questionários foram veiculados eletronicamente, no início de 2017, por e-mail e/ou plataformas equivalentes, para um potencial público de respondentes composto por cerca de 400 (quatrocentos) recrutadores (headhunters e gerentes de recursos humanos) de companhias de todo o país, que foram recrutados através da rede profissional LinkedIn sendo que, desses foi obtida uma amostra de 47 (quarenta e sete) respondentes. Utilizou-se para a análise dos resultados o método de análise qui-quadrado (ou distribuição $\mathrm{x}^{2}$, como também é conhecida), que permite explorar as demais relações existentes entre as variáveis, excetuando-se, é claro, as relações de causa e efeito.

O método de análise qui-quadrado representa um teste de hipóteses onde propõe-se encontrar o valor da dispersão para duas variáveis nominais, avaliando a associação existente entre variáveis qualitativas, não dependendo de parâmetros populacionais, como média e variância. $\mathrm{O}$ princípio básico deste método é comparar as possíveis divergências entre as frequências observadas e esperadas para um certo evento. Portanto, o teste é utilizado para verificar se a frequência com que um determinado acontecimento observado em uma amostra se desvia significativamente ou não da frequência com que ele é esperado (Taylor, 1997).

\section{ANÁLISE DOS RESULTADOS}

A partir do questionário aplicado, apresenta-se a seguir primeiramente, o perfil dos respondentes da pesquisa, e posteriormente as observações encontradas nos questionamentos efetuados. Dos 47 recrutadores $27,7 \%$ são do sexo masculino e $72,3 \%$ são do sexo feminino. No que diz respeito à região que estes recrutadores residem, 59,6\% são da região Sudeste, sendo que desses 53,2\% são do estado de São Paulo, 21,3\% são da região Sul e o restante, $19,1 \%$, são das regiões Centro-Oeste, Norte e Nordeste. No que diz respeito à faixa etária dos respondentes cerca de $80 \%$ tem idade superior a 31 anos, os dados são apresentados na Tabela 1. 
Tabela 1. Distribuição da faixa etária dos respondentes

\begin{tabular}{cc}
\hline Faixa Etária & Fi(\%) \\
\hline até 30 anos & $19,1 \%$ \\
31 a 35 anos & $23,4 \%$ \\
36 a 40 anos & $19,1 \%$ \\
41 a 50 anos & $21,3 \%$ \\
51 a 60 anos & $14,9 \%$ \\
Mais de 60 anos & $2,1 \%$ \\
\hline
\end{tabular}

Fonte: Dados da pesquisa.

Para facilitar o entendimento e análise segregou-se a amostra em duas possibilidades de atuação, "headhunter" e "profissional atuando no RH de alguma empresa", encontrou-se uma distribuição percentual de $51,1 \%$ e $48,9 \%$, respectivamente. Para cada possibilidade de atuação foram feitos questionamentos a respeito das organizações onde atuam, atividades desenvolvidas e nível hierárquico ao qual pertencem no organograma da empresa.

Primeiramente, são apresentados os dados obtidos para os respondentes que atuam como profissionais de RH. Com base nos dados obtidos pelas pesquisas as empresas nas quais esses profissionais atuam são de comércio (34,8\%), serviço (30,4\%), indústria $(30,4 \%)$ e agronegócios $(4,3 \%)$ e a maioria delas tem mais de 1.000 funcionários conforme Tabela 2.

Tabela 2. Número de funcionários das organizações dos respondentes na área de RH

\begin{tabular}{cc}
\hline Número de funcionários na empresa & $\%$ \\
\hline até 100 funcionários & $4,3 \%$ \\
de 101 a 250 funcionários & $13,0 \%$ \\
de 251 a 500 funcionários & $13,0 \%$ \\
de 501 a 1.000 funcionários & $17,4 \%$ \\
mais de 1.000 funcionários & $52,2 \%$ \\
\hline
\end{tabular}

Fonte: Dados da pesquisa.

Dado que o processo de seleção e contratação - foco desse estudo - geralmente depende do nível hierárquico do respondente foi solicitado que este indicasse quantos níveis hierárquicos o separam do principal executivo de $\mathrm{RH}$. A maior parte $(39,1 \%)$ é o principal executivo de RH ou está no mesmo nível hierárquico, 26,1\% está a um nível de separação, $30 \%$ está a dois níveis e 4,3\% estão a 3 níveis. Dado o nível hierárquico 56,5\% responderam ser o principal tomador de decisões da área, enquanto 43,5\% estão a um nível abaixo deste.

Finda a apresentação dos dados obtidos para os respondentes que atuam como profissionais de $\mathrm{RH}$ são apresentados os dados obtidos para os profissionais que declararam atuar como headhunters. Ao contrário dos profissionais de $\mathrm{RH}$, os headhunters atuam em empresas menores, prestadoras de serviço de recrutamento, sendo a maioria com menos de 100 funcionários, os dados relativos ao tamanho da empresa são apresentados na Tabela 3.

Tabela 3. Número de funcionários das organizações dos respondentes na área dos headhunters

\begin{tabular}{cc}
\hline Número de funcionários na empresa & $\%$ \\
\hline Até 5 funcionários & $34,8 \%$ \\
de 6 a 10 funcionários & $17,4 \%$ \\
de 11 a 50 funcionários & $4,3 \%$ \\
de 51 a 100 funcionários & $8,7 \%$ \\
mais de 100 funcionários & $34,8 \%$ \\
\hline
\end{tabular}

Fonte: Dados da pesquisa. 
Outro ponto analisado na caracterização desses profissionais foi a respeito das atividades realizadas por estes, sendo a resposta com maior frequência "Processo de recrutamento e seleção". É importante esclarecer que quando questionados acerca das atividades desenvolvidas na sua atuação como headhunter, demonstrada na Tabela 4, foi lhes permitido optar por mais de uma alternativa como resposta.

Tabela 4. Atividades desenvolvidas pelos headhunters

\begin{tabular}{cc}
\hline Atividades Desenvolvidas & $\%$ \\
\hline Processos de Captação de Vagas & $58,30 \%$ \\
Gerenciamento de Bases de Dados de Candidatos & $58,30 \%$ \\
Processo de Recrutamento e Seleção & $91,70 \%$ \\
Gerenciamento/Aconselhamento de Carreira & $41,70 \%$ \\
\hline
\end{tabular}

Fonte: Dados da pesquisa.

As atividades que envolvem o trabalho de profissionais de headhunter são diversos, e envolvem atividades que tem relação direta com os contratantes, que indicam suas demandas, e os que tem relação direta com possíveis candidatos. Os dados da Tabela 4 demonstram que os profissionais que participaram da pesquisa atuam em diversas frentes, o que permite avaliar seu envolvimento com as necessidades de mercado e a realidade encontrada.

\subsection{Análise das habilidades}

Ao analisar o subgrupo habilidades, nota-se que as habilidades esperadas de maior importância para os recrutadores do profissional contábil são comprometimento, habilidade com planilhas eletrônicas, trabalho em equipe, resolução de problemas e proatividade, respectivamente. As classificações das habilidades são apresentadas na Tabela 5.

Tabela 5. Relevância das habilidades

\begin{tabular}{ccccc}
\hline Habilidades & Muito Relevante & Relevante & Pouco Relevante & Irrelevante \\
\hline Comprometimento & $74,50 \%$ & $23,40 \%$ & $2,10 \%$ & $0,00 \%$ \\
Planilhas Eletrônicas & $66,00 \%$ & $34,00 \%$ & $0,00 \%$ & $0,00 \%$ \\
Trabalhar em Equipe & $59,60 \%$ & $38,30 \%$ & $2,10 \%$ & $0,00 \%$ \\
Resolução de Problemas & $53,20 \%$ & $46,80 \%$ & $0,00 \%$ & $0,00 \%$ \\
Proatividade & $53,20 \%$ & $44,70 \%$ & $2,10 \%$ & $0,00 \%$ \\
Autogerenciamento & $38,30 \%$ & $51,10 \%$ & $10,60 \%$ & $0,00 \%$ \\
Pensamento Crítico & $34,00 \%$ & $59,60 \%$ & $4,30 \%$ & $2,10 \%$ \\
Comunicação Oral & $34,00 \%$ & $51,10 \%$ & $14,90 \%$ & $0,00 \%$ \\
Tomar Decisões & $34,00 \%$ & $42,60 \%$ & $23,40 \%$ & $0,00 \%$ \\
Comunicação Escrita & $29,80 \%$ & $68,10 \%$ & $2,10 \%$ & $0,00 \%$ \\
Espírito de Liderança & $14,90 \%$ & $48,90 \%$ & $36,20 \%$ & $0,00 \%$ \\
\hline
\end{tabular}

Fonte: Dados da pesquisa.

Com base no exposto na Tabela 5, observa-se que as expectativas do mercado acerca das habilidades mais importantes não estão alinhadas com a Resolução CNE/CES 10 de 16 de dezembro de 2004 que institui as diretrizes curriculares nacionais para o curso de graduação em Ciências Contábeis. Apesar de o desalinhamento entre as diretrizes curriculares e as expectativas de mercado, observa-se na Tabela 6 que as habilidades mais buscadas pelo mercado estão sendo desenvolvidas pelas IES. 
Tabela 6. Adequação das habilidades de acordo com os respondentes

\begin{tabular}{ccc}
\hline Habilidade & Adequada & Inadequada \\
\hline Comprometimento & $85,10 \%$ & $14,90 \%$ \\
Planilhas Eletrônicas & $72,30 \%$ & $27,70 \%$ \\
Trabalhar em Equipe & $63,80 \%$ & $36,20 \%$ \\
Proatividade & $59,60 \%$ & $40,40 \%$ \\
Comunicação Escrita & $57,40 \%$ & $42,60 \%$ \\
Comunicação Oral & $51,10 \%$ & $48,90 \%$ \\
Pensamento Crítico & $48,90 \%$ & $51,10 \%$ \\
Tomar Decisões & $46,80 \%$ & $53,20 \%$ \\
Autogerenciamento & $44,70 \%$ & $55,30 \%$ \\
Resolução de Problemas & $40,40 \%$ & $59,60 \%$ \\
Espírito de Liderança & $38,30 \%$ & $61,70 \%$ \\
\hline
\end{tabular}

Fonte: Dados da pesquisa.

As três habilidades com maior nível de inadequação, como observa-se na Tabela 6 , são o autogerenciamento, a resolução de problemas e o espírito de liderança. Tal resultado sugere que apesar das mudanças exigidas pelo mercado, as IES continuam formando seus estudantes para serem o bookkeeper, ou seja, um profissional pouco reflexivo, que não assume a liderança de equipes e não é voltado para a resolução de problemas. Tais habilidades apesar de serem colocadas como importantes pelo mercado não aparecem nas DCNs, podendo indicar uma defasagem nas mesmas, visto que tais diretrizes são pré-IFRS.

Tal resultado é problemático, pois sugere que as IES continuam adotando uma concepção de ensino com tendência reprodutivista e tecnicista - cenário que caracterizava o ensino de Contabilidade em 1970 (Silva, 2015). Essa formação tecnicista e focada em conteúdo que privilegia a especialização conteudista em detrimento de uma formação humanística e crítica "responde adequadamente ao modelo empresarial e de mercado que cada vez mais pressiona o ensino superior no mundo ocidental a partir da hegemonia neoliberal" (Cunha, 2000, p. 45). Por fim, tal lógica de ensino ainda vai na contramão da proposta de um currículo baseado em competências como apresentada por Lawson et al. (2015).

Aprofundando-se a análise do subgrupo Habilidades, fez-se uma análise utilizando o método qui-quadrado comparando as respostas pela atuação - headhunter ou RH - dos recrutadores respondentes, visto que como demonstrado na apresentação da amostra cada perfil de respondente apresenta suas particularidades. Ao analisar importância (expectativa) dessas habilidades na visão do profissional que atua no RH de alguma empresa em comparação com as do headhunter percebe-se que as únicas habilidades que apresentaram diferenças estatisticamente significativas ( $\mathrm{p}$-valor $<0,005)$ foram as habilidades planilhas eletrônicas e autogerenciamento, conforme dados apresentados na Tabela 7.

Tabela 7. Nível de significância das diferenças

\begin{tabular}{cc}
\hline Habilidade & p valor \\
\hline Comprometimento & 0,515 \\
Planilhas Eletrônicas & 0,049 \\
Trabalhar em Equipe & 0,295 \\
Resolução de Problemas & 0,891 \\
Proatividade & 0,205 \\
Autogerenciamento & 0,028 \\
Pensamento Crítico & 0,615 \\
Comunicação Oral & 0,866
\end{tabular}


Fonte: Dados da pesquisa.

Tomar Decisões

Comunicação Escrita

Espírito de Liderança
0,197

0,325

0,707

$\mathrm{Na}$ tentativa de facilitar a compreensão dos fundamentos por trás dessas discrepâncias, confrontou-se a frequência das respostas para cada um desses profissionais em relação à cada uma das habilidades. Por meio dessa comparação, percebe-se que as discrepâncias ocorreram devido à frequência elevada de respostas dos headhunters classificando a habilidade com planilhas eletrônicas como muito relevante, em contrapartida ao alto percentual de respostas dos profissionais atuantes no $\mathrm{RH}$ classificando a habilidade de autogerenciamento como muito relevante, conforme apresentado na Tabela 8.

Tabela 8. Comparação da percepção entre os profissionais

\begin{tabular}{llcc}
\hline Habilidade & Classificação & Headhunter & Profissionais de RH \\
\hline \multirow{2}{*}{ Planilhas eletrônicas } & Relevante & $20,80 \%$ & $47,80 \%$ \\
& Muito Relevante & $79,20 \%$ & $52,20 \%$ \\
\hline \multirow{2}{*}{ Autogerenciamento } & Pouco relevante & $20,80 \%$ & $0,00 \%$ \\
& Relevante & $54,20 \%$ & $47,80 \%$ \\
& Muito Relevante & $25,00 \%$ & $52,20 \%$ \\
\hline
\end{tabular}

Fonte: Dados da pesquisa.

A partir da Tabela 8 , observa-se que existe um consenso acerca da necessidade de o profissional recém-formado ter desenvolvido suas habilidades com as planilhas eletrônicas, visto que ao somar as respostas "relevante" e "muito relevante" atinge-se $100 \%$ entre os respondentes da pesquisa. Observa-se também que o autogerenciamento é colocado como pouco relevante para $20,80 \%$ dos respondentes headhunters enquanto os profissionais de $\mathrm{RH}$ mantêm a concordância de $100 \%$, podendo indicar que a habilidade pode ser requerida por algumas empresas e por outras não.

Aplicou-se esse mesmo método de análise qui-quadrado para as respostas acerca da adequação (realidade) encontrada dessas habilidades na visão do profissional que atua no RH de alguma empresa em comparação com as do headhunter. A partir da Tabela 9, percebe-se que também há diferença significativa $(\mathrm{p}$ valor $<0,005)$ entre a adequação encontrada para a habilidade comunicação-oral na concepção desses recrutadores.

Tabela 9. Adequação das habilidades de acordo com os respondentes pelo método do $\mathrm{x}^{2}$

\begin{tabular}{cc}
\hline Habilidade & p valor \\
\hline Comprometimento & 0,727 \\
Planilhas Eletrônicas & 0,123 \\
Trabalhar em Equipe & 0,846 \\
Resolução de Problemas & 0,859 \\
Proatividade & 0,440 \\
Autogerenciamento & 0,312 \\
Pensamento Crítico & 0,664 \\
Comunicação Oral & 0,013 \\
Tomar Decisões & 0,089 \\
Comunicação Escrita & 0,900 \\
Espírito de Liderança & 0,278 \\
\hline
\end{tabular}

Fonte: Dados da pesquisa. 
Na concepção dos headhunters o profissional contábil tem apresentado a habilidade comunicação oral de forma inadequada - apenas $33 \%$ dos respondentes a classificaram como adequada -, enquanto na concepção do profissional atuante no RH essa habilidade tem sido adequada - cerca de $70 \%$ a classificaram com adequada. $\mathrm{O}$ desenvolvimento da habilidade de comunicação em estudantes de Contabilidade foi analisado por Lima, Vendramin e Miranda (2020). Os resultados encontrados pelos autores indicam a existência do fenômeno "communication aprehension", sendo que tal fenômeno aponta para a ansiedade trazida pela necessidade de se comunicar em determinadas situações e pode atrapalhar o desenvolvimento dessa habilidade (Lima, Vendramin, \& Miranda, 2020). Considerando a existência do fenômeno em estudantes de graduação é possível que tal fenômeno também se aplique para os recém-formados.

\subsection{Análise da formação}

No subgrupo formação denominam-se por "Pontos de Currículo" as possíveis características encontradas no perfil do profissional contábil nesse subgrupo. Ao analisar este subgrupo levar-se-á em conta principalmente a somatória das frequências de "Muito Relevante" e "Relevante" quando tratar-se da importância (expectativa) que tais características representam no perfil do profissional para os respondentes, e, "Alta" e "Média" quando da frequência (realidade) encontrada, conforme dados apresentados na Tabela 10.

Tabela 10. Comparação entre os pontos de currículo esperados e os pontos encontrados

\begin{tabular}{|c|c|c|c|c|c|c|c|c|}
\hline \multirow{2}{*}{$\begin{array}{l}\text { Pontos de } \\
\text { Currículo }\end{array}$} & \multicolumn{4}{|c|}{ Expectativa } & \multicolumn{4}{|c|}{ Realidade } \\
\hline & $\begin{array}{c}\text { Muito } \\
\text { Relevante }\end{array}$ & Relevante & $\begin{array}{c}\text { Pouco } \\
\text { Relevante }\end{array}$ & $\begin{array}{c}\text { Irrele- } \\
\text { vante }\end{array}$ & Alta & Média & Baixa & $\begin{array}{c}\text { Ausente } \\
\text { /Rara }\end{array}$ \\
\hline Empresa Júnior & $10,60 \%$ & $27,70 \%$ & $44,70 \%$ & $17,00 \%$ & $4,30 \%$ & $17,00 \%$ & $61,70 \%$ & $17,00 \%$ \\
\hline Intercâmbio & $10,60 \%$ & $31,90 \%$ & $42,60 \%$ & $14,90 \%$ & $4,30 \%$ & $19,10 \%$ & $48,90 \%$ & $27,70 \%$ \\
\hline $\begin{array}{l}\text { Entidades } \\
\text { (Centro } \\
\text { Acadêmico e } \\
\text { Atlética) }\end{array}$ & $2,10 \%$ & $12,80 \%$ & $51,10 \%$ & $34,00 \%$ & $4,30 \%$ & $10,60 \%$ & $55,30 \%$ & $29,80 \%$ \\
\hline MBA & $21,30 \%$ & $51,10 \%$ & $23,40 \%$ & $4,20 \%$ & $4,30 \%$ & $44,70 \%$ & $46,80 \%$ & $4,30 \%$ \\
\hline Mestrado & $10,60 \%$ & $23,40 \%$ & $46,80 \%$ & $19,20 \%$ & $0,00 \%$ & $19,10 \%$ & $48,90 \%$ & $32,00 \%$ \\
\hline Inglês & $42,60 \%$ & $38,30 \%$ & $14,90 \%$ & $4,20 \%$ & $2,10 \%$ & $21,30 \%$ & $59,60 \%$ & $17,00 \%$ \\
\hline Outras Línguas & $4,30 \%$ & $27,70 \%$ & $53,20 \%$ & $14,80 \%$ & $0,00 \%$ & $4,30 \%$ & $61,70 \%$ & $34,00 \%$ \\
\hline Outros Cursos & $27,70 \%$ & $63,80 \%$ & $8,50 \%$ & $0,00 \%$ & $10,60 \%$ & $53,20 \%$ & $34,00 \%$ & $2,20 \%$ \\
\hline $\begin{array}{l}\text { Trabalho } \\
\text { Voluntário }\end{array}$ & $4,30 \%$ & $19,10 \%$ & $51,10 \%$ & $25,50 \%$ & $0,00 \%$ & $19,10 \%$ & $48,90 \%$ & $32,00 \%$ \\
\hline $\begin{array}{l}\text { Registro no } \\
\text { CRC }\end{array}$ & $72,30 \%$ & $19,10 \%$ & $8,60 \%$ & $0,00 \%$ & $38,30 \%$ & $46,80 \%$ & $14,90 \%$ & $0,00 \%$ \\
\hline Estágio & $59,60 \%$ & $36,20 \%$ & $4,20 \%$ & $0,00 \%$ & $31,90 \%$ & $53,20 \%$ & $14,90 \%$ & $0,00 \%$ \\
\hline
\end{tabular}

Fonte: Dados da pesquisa.

A partir Tabela 10 percebe-se que de todas as características pertencentes ao subgrupo formação a que apresenta defasagem mais significativa, quando comparamos expectativa e realidade, é a fluência do profissional na língua inglesa, o que ganha ainda mais relevância quando levado em consideração a importância que o conhecimento do idioma estrangeiro ganhou principalmente a partir da conversão às IFRS. A Tabela 11 facilita a percepção dessas 
defasagens entre o perfil esperado e o perfil encontrado nos profissionais das ciências contábeis.

Tabela 11. Importância x Frequência dos pontos de currículo

\begin{tabular}{ccc}
\hline Pontos de Currículo & Importância & Realidade \\
\hline Empresa Júnior & $38,30 \%$ & $21,30 \%$ \\
Intercâmbio & $42,50 \%$ & $23,40 \%$ \\
Entidades (C.A. e Atlética) & $14,90 \%$ & $14,90 \%$ \\
MBA & $72,40 \%$ & $49,00 \%$ \\
Mestrado & $34,00 \%$ & $19,10 \%$ \\
Inglês & $80,90 \%$ & $23,40 \%$ \\
Outras Línguas & $32,00 \%$ & $4,30 \%$ \\
Outros Cursos & $91,50 \%$ & $63,80 \%$ \\
Trabalho Voluntário & $23,40 \%$ & $19,10 \%$ \\
CRC & $91,40 \%$ & $85,10 \%$ \\
Estágio & $95,80 \%$ & $85,10 \%$ \\
\hline
\end{tabular}

Fonte: Dados da pesquisa.

A Tabela 11 apresenta os dados da Tabela 10 de forma consolidada, a informação de importância consolida a importância muito relevante e relevante, e as realidades alta e média. A partir da Tabela 11 percebe-se ainda que a participação do profissional em entidades estudantis (Centro Acadêmico e/ou Atlética), em cujo perfil encontrado não sofre qualquer variação em comparação ao perfil esperado. Todavia, como aponta Moura (2010), a participação em entidades estudantis é um fator determinante para a formação das habilidades sociais dos estudantes (futuros profissionais), dentre as quais se destacam, por exemplo, comprometimento e trabalho em equipe, habilidades que, na percepção dos recrutadores, são as de maior importância.

Como realizado anteriormente com o subgrupo Habilidades, o subgrupo Formação também foi analisado através do método qui-quadrado, comparando as respostas pela atuação (headhunter ou $\mathrm{RH}$ ) dos recrutadores respondentes conforme realizado no trabalho de Montano et al. (2001). Primeiramente, serão apresentados os resultados da aplicação do método de análise qui-quadrado para as respostas acerca da importância (expectativa) desses pontos de currículo na visão do profissional que atua no $\mathrm{RH}$ de alguma empresa em comparação com as do headhunter.

A Tabela 12 evidencia que há discrepâncias ( $\mathrm{p}$ valor $<0,05$ ) entre as opiniões do quão relevante são os pontos de currículo de fluência na língua inglesa e realização de estágio na área contábil.

Tabela 12. Comparação entre headhunters e profissionais de RH

\begin{tabular}{cc}
\hline Pontos de Currículo & p valor \\
\hline Empresa Júnior & 0,583 \\
Intercâmbio & 0,132 \\
Entidades (C.A. e Atlética) & 0,559 \\
MBA & 0,768 \\
Mestrado & 0,775 \\
Inglês & 0,049 \\
Outras Línguas & 0,136 \\
Outros Cursos & 0,296 \\
Trabalho Voluntário & 0,302
\end{tabular}




\begin{tabular}{rc} 
CRC & 0,58 \\
Estágio & 0,046 \\
\hline Fonte: Dados da pesquisa
\end{tabular}

Para facilitar a compreensão dessas discrepâncias, novamente confrontou-se a frequência das respostas para cada um desses profissionais (headhunter e $\mathrm{RH}$ ), em relação àqueles pontos de currículo. Como pode ser visto na Tabela 13, as discrepâncias ocorreram devido à frequência elevada de respostas dos headhunters classificando os pontos de currículo de fluência na língua inglesa e realização de estágio na área contábil como muito relevante.

Tabela 13. Comparação entre Headhunter e Profissionais de RH sobre as habilidades

\begin{tabular}{cccccc}
\hline Habilidade & Classificação & \multicolumn{2}{c}{ Headhunters } & \multicolumn{2}{c}{ Profissionais de RH } \\
\hline \multirow{3}{*}{ Inglês } & Irrelevante & $0,00 \%$ & \multirow{2}{*}{$4,2 \%$} & $8,70 \%$ & \multirow{2}{*}{$34,8 \%$} \\
& Pouco Relevante & $4,20 \%$ & & $26,10 \%$ & \\
& Relevante & $41,60 \%$ & \multirow{2}{*}{$95,8 \%$} & $34,80 \%$ & \multirow{2}{*}{$65,2 \%$} \\
& Muito Relevante & $54,20 \%$ & & $30,40 \%$ & \\
\multirow{2}{*}{ Estágio } & Relevante & $20,80 \%$ & & $52,20 \%$ & \\
& Muito Relevante & $70,80 \%$ & & $47,80 \%$ & \\
\hline
\end{tabular}

Fonte: Dados da pesquisa.

Aplicou-se a análise de qui-quadrado para as respostas acerca da adequação (realidade) encontrada desses pontos de currículo na visão do profissional que atua no RH de alguma empresa em comparação com as do headhunter. A partir da Tabela 14, percebe-se que também há discrepância entre a adequação encontrada para o ponto de currículo de realização de estágio na área contábil na concepção desses recrutadores.

Tabela 14. Análise das diferenças pelo qui-quadrado

\begin{tabular}{cc}
\hline Pontos de Currículo & p valor \\
\hline Empresa Júnior & 0,342 \\
Intercâmbio & 0,759 \\
Entidades (C.A. e Atlética) & 0,782 \\
MBA & 0,976 \\
Mestrado & 0,905 \\
Inglês & 0,583 \\
Outras Línguas & 0,993 \\
Outros Cursos & 0,167 \\
Trabalho Voluntário & 0,444 \\
CRC & 0,769 \\
Estágio & 0,013 \\
\hline
\end{tabular}

Fonte: Dados da pesquisa.

Na concepção dos headhunters o profissional contábil tem apresentado experiência profissional insuficiente por meio de estágios na área contábil - apenas $12,50 \%$ dos respondentes dessa categoria a classificaram como alta -, enquanto que na concepção do profissional atuante no RH esse ponto de currículo teria se mostrado adequado - 52,20\% dos respondentes dessa categoria a classificaram como alta. Segundo Caires e Almeida (2000, p. 220), para articular "experiência de trabalho e a formação teórica veiculada no contexto universitário", o estágio surge como um espaço privilegiado para a sua concretização, o que ratifica a percepção dos respondentes no sentido de a realização de estágio é média ou alta relevância. 
Finalizando a análise do subgrupo Formação, a Tabela 15 apresenta a importância (expectativa) dos últimos pontos de currículo na opinião dos recrutadores. Considerando-se ainda a somatória das frequências de "Muito Relevante" e "Relevante" - por tratar-se da importância (expectativa) que tais características representam no perfil do profissional para os respondentes -, é evidente a importância dada para a graduação em universidades de prestígio, ainda que a mesma importância não se estenda as médias dos estudantes. Todavia, mais importante ainda são as recomendações que o profissional da área contábil possui - totalizando mais de $80 \%$ entre a soma de muito relevante e relevante.

Tabela 15. Importância de outros pontos de currículo de acordo com os respondentes

\begin{tabular}{ccccc}
\hline Pontos de Currículo & Muito Relevante & Relevante & Pouco Relevante & Irrelevante \\
\hline Universidade & $25,50 \%$ & $51,10 \%$ & $19,10 \%$ & $4,30 \%$ \\
Média Ponderada Geral & $10,60 \%$ & $29,80 \%$ & $48,90 \%$ & $10,70 \%$ \\
Média Ponderada Específica & $12,80 \%$ & $23,40 \%$ & $53,20 \%$ & $10,60 \%$ \\
Recomendações & $17,00 \%$ & $66,00 \%$ & $14,90 \%$ & $2,10 \%$ \\
\hline
\end{tabular}

Fonte: Dados da pesquisa.

Como se vê, em resumo, em mais de uma oportunidade foram identificadas divergências significativas entre o perfil encontrado e o perfil esperado dos profissionais das ciências contábeis, mais ainda de acordo com a natureza dos respondentes. Oliveira (2011) também encontrou diferenças significativas, ecoando a crítica de Montano et al. (2001), quanto ao preparo dos profissionais da contabilidade.

Muitas das divergências encontradas estão relacionadas às soft skills, e estudos como os de Pereira et al. (2012) e Castro et al. (2009) apontam que o ensino tradicional ainda é a metodologia mais utilizada nas universidades e não há a ênfase adequada nas universidades no desenvolvimento das soft skills (Pant \& Baroudi, 2008). Rhodes (2015) reforça que os alunos de Ciências Contábeis não possuem contato satisfatório com uma aprendizagem que considere a empregabilidade a longo prazo. Dessa forma pode-se avaliar que a academia não está oferecendo adequadamente as exigências de mercado. Briggs, Copeland e Haynes (2007, p. 511), ainda afirmam que "não estamos atraindo e mantendo o que a profissão contábil precisa, ou não estamos dando aos alunos matriculados a oportunidade de desenvolver as habilidades necessárias".

\section{CONSIDERAÇÕES FINAIS}

A partir das análises realizadas na seção anterior conclui-se que, em se tratando das habilidades do profissional contábil a expectativa que os recrutadores esperam do perfil desse profissional têm sido satisfatórias quando comparadas com a realidade que esses mesmos recrutadores encontram no mercado, à exceção da habilidade de resolução de problemas, que apesar de extremamente relevante para o profissional nessa área de atuação, não se mostra adequada às expectativas dos respondentes.

Tratando-se dos pontos de currículo, é evidente que a defasagem mais preocupante hoje para o profissional contábil é a fluência na língua inglesa. Antes visto como um diferencial, hoje o domínio da língua inglesa tornou-se exigência básica no mercado de trabalho, não apenas em razão do processo de conversão às normas IFRS, mas também porque a globalização trouxe conexões e ampliou as fronteiras. É importante ressaltar que há divergências nas concepções tanto de importância (expectativa) como da realidade encontrada nos pontos de currículo pelos recrutadores quando segregados a partir da sua atuação (headhunter e profissional de $\mathrm{RH}$ ), provavelmente em razão das experiências que cada um deles possui e 
diferenças nas atividades e tomadas de decisão nos processos de recrutamento nas organizações.

Em se tratando da pouca importância (expectativa) que os recrutadores dão para certas habilidades e/ou pontos de currículo que não apresentaram frequência de respostas significativas, isso não deve implicar em desvalorização ou até mesmo desmotivação dos estudantes ou profissionais no seu desenvolvimento. Tome-se, por exemplo, a participação em entidades estudantis, que apesar de não apresentar grande relevância na visão dos respondentes, é um fator determinante para a formação das habilidades sociais dos futuros profissionais (Moura, 2010), dentre as quais se destacam, por exemplo, comprometimento e trabalho em equipe, habilidades que, na percepção dos recrutadores, são as de maior importância.

O objetivo proposto para o trabalho, foi o de analisar a percepção dos profissionais de recrutamento e seleção acerca das habilidades mais importantes do profissional contábil recémformado, e o estudo conseguiu demonstrar poucas divergências entre estes profissionais, sobre quais seriam as habilidades mais esperadas, e o que tem sido encontrado. Porém, ambos profissionais reforçam as diferenças entre a formação e as habilidades esperadas.

Essas divergências precisam ser investigadas, no sentido de avaliar entre coordenadores de curso, se essas demandas estão sendo ou não ofertadas em seus projetos pedagógicos de curso, que provavelmente foram embasados nas DCN do curso datadas de 2004, que precisariam ou não ser revisadas. Como possíveis trabalhos futuros, sugere-se além de uma pesquisa com maior amplitude de profissionais, que também se façam análises para necessidades de mercado para profissionais com mais tempo de mercado, além da avaliação de coordenadores de curso, sobre suas avaliações sobre o tema.

Em outras palavras, é possível concluir que os estudos realizados nessa linha de pesquisa contribuem com o aprimoramento e adaptação das academias (universidades) no preparo do aluno (futuro profissional) para o perfil que o mercado tem esperado do profissional das ciências contábeis. Essa demanda é ainda mais necessária em um mundo que vem sofrendo grandes mudanças e adequações ao ritmo e perfil das novas gerações, sob pena de o processo de produção de conhecimento e formação técnica tradicional de nossas universidades não mais oferecer as ferramentas necessárias para o mercado de trabalho.

\section{REFERÊNCIAS}

Avelino, B. C., Santana, G. A. S., Colauto, R. D., \& Madeira, G. J. (2012). Análise do perfil dos estudantes em Ciências Contábeis e sua relação com o processo de convergência das normas contábeis. Revista Brasileira de Contabilidade, (182), 62-77.

Beuren, I. M. (2013). Como elaborar trabalhos monográficos em contabilidade. Editora Atlas SA.

Briggs, S. P., Copeland, S., \& Haynes, D. (2007). Accountants for the 21 st century, where are you? A five-year study of accounting students' personality preferences. Critical Perspectives on Accounting, 18(5), 511-537.

Brown, R. (Ed.). (2014). A history of accounting and accountants. Routledge.

Caires, S., \& Almeida, L. S. (2000). Os estágios na formação dos estudantes do ensino superior: tópicos para um debate em aberto. Revista Portuguesa de Educação, 13(2), 219-241.

Cardoso, R. L., Riccio, E. L., \& De Albuquerque, L. G. (2009). Competências do contador: um estudo sobre a existência de uma estrutura de interdependência. Revista de AdministraçãoRAUSP, 44(4), 365-379. 
Castro, R. C. S., Echternacht, T. H. S., \& Brito, C. A. O. (2009). Desenvolvimento de Habilidades e Competências Para a Prática Contábil: Uma Pesquisa Empírica Numa Instituição Pública Brasileira. Revista de Informação Contábil, 3(2), 61-82.

Cloete, M. (2018). The impact of an integrated assessment on the critical thinking skills of firstyear university students. Accounting Education, 27(5), 479-494.

Coady, P., Byrne, S., \& Casey, J. (2018). Positioning of emotional intelligence skills within the overall skillset of practice-based accountants: employer and graduate requirements. Accounting Education, 27(1), 94-120.

Cook, E. D., \& Finch, B. (1994). Qualities employers seek in new accounting employees. Journal of Education for Business, 69(3), 136-139.

Cotrin, A. M., Santos, A. L., \& Zotte Junior, L. (2012). A evolução da contabilidade e o mercado de trabalho para o contabilista. Revista Conteúdo, Capivari, 2(1), 44.

Cunha, M. I. (2000). Ensino como mediação da formação do professor universitário. Professor do ensino superior: identidade, docência e formação. Brasília: INEP, 45-51.

Davidson, R. A. (1994). Use of perceptions in employee selection by accounting firms. Canadian Journal of Administrative Sciences/Revue Canadienne des Sciences de l'Administration, 11(4), 331-338.

De Rocchi, C. A. (2007). Transferência internacional de tecnologia contábil: um estudo comparativo numa perspectiva geográfico - temporal. (Tese de Doutorado). Programa de Pós-Graduação em Engenharia de Produção, Universidade Federal de Santa Catarina, Florianópolis, SC.

Deluiz, N. (2001). Qualificação, competências e certificação: visão do mundo do trabalho. Formação, 1(2), 5-15.

Depresbiteris, L. (2001). Avaliando competências na escola de alguns ou na escola de todos?. Boletim Técnico do SENAC, 27(3), 36-47.

Douglas, S., \& Gammie, E. (2019). An investigation into the development of non-technical skills by undergraduate accounting programmes. Accounting education, 28(3), 304-332.

Ericeira, F. J. (2003). O estado da arte da contabilidade no Estado do Maranhão, vis-à-vis seu desenvolvimento econômico. (Dissertação de Mestrado). Faculdade de Economia, Administração e Contabilidade da Universidade de São Paulo, São Paulo, SP.

Fleury, M. T. L., \& Fleury, A. (2001). Construindo o conceito de competência. Revista de Administração Contemporânea, 5(spe), 183-196.

Hardin, J. R., Reding, K. F., \& Stocks, M. H. (2002). The effect of gender on the recruitment of entry-level accountants. Journal of Managerial Issues, 251-266.

Ibrahim, N., \& Angelidis, J. (2009). The relative importance of ethics as a selection criterion for entry-level public accountants: Does gender make a difference?. Journal of Business Ethics, 85(1), 49-58.

Jackling, B., Howieson, B., \& Natoli, R. (2012). Some implications of IFRS adoption for accounting education. Australian Accounting Review, 22(4), 331-340.

Kruger, S. D., Mazzioni, S., Resende, A., Gubiani, C. A., \& Zanin, A. (2013). O perfil desejado do egresso dos cursos de ciências contábeis das Universidades de Santa Catarina. Revista Catarinense da Ciência Contábil, 12(34), 40-52. 
Lawson, R. A., Blocher, E. J., Brewer, P. C., Morris, J. T., Stocks, K. D., Sorensen, J. E., ... \& Wouters, M. J. (2015). Thoughts on competency integration in accounting education. Issues in Accounting Education, 30(3), 149-171.

Le Boterf, G. (2003). Desenvolvendo a competência dos profissionais. Artmed.

Lim, Y., Lee, T. H., Yap, C. S., \& Ling, C. C. (2016). Employability skills, personal qualities, and early employment problems of entry-level auditors: Perspectives from employers, lecturers, auditors, and students. Journal of Education for Business, 91(4), 185. https://doi.org/10.1080/08832323.2016.1153998

Lim, Y. M., Cham, T. H., Lee, T. H., Ramalingam, T., \& Latha, C. (2019). Employer-Employee Perceptual Differences in Job Competency: A Study of Generic Skills, Knowledge Required, and Personal Qualities for Accounting-Related Entry-Level Job Positions. International Journal of Academic Research in Accounting, Finance and Management Sciences, 9(4), 73-83. http://dx.doi.org/10.6007/IJARAFMS/v9-i4/6660

Lima, J. P. R., Vendramin, E. O., \& Miranda, C. S. (2021). Quem tem medo de se comunicar? Análise da apreensão na comunicação de estudantes de Ciências Contábeis. Sociedade, Contabilidade e Gestão, 16(1). 105-120.

Lopes de Sá, A. (2009). Tecnologia contábil contemporânea. Curitiba: Juruá.

Marin, T. I. S., Lima, S. J., \& Nova, S. P. C. C. (2014). Formação do Contador-o que o Mercado quer, é o que ele tem? um Estudo sobre o Perfil Profissional dos Alunos de Ciências Contábeis da FEA-USP. Contabilidade Vista \& Revista, 25(2), 59-83.

Martin, N. C. (2002). Da contabilidade à controladoria: a evolução necessária. Revista Contabilidade \& Finanças, 13(28), 7-28.

Mattessich, R. (1989). Accounting and the input—output principle in the prehistoric and ancient world. Abacus, 25(2), 74-84.

Meurer, A. M., \& Voese, S. B. (2020). Há vagas: análise do perfil profissional requerido pelo mercado de trabalho para profissionais contábeis da área de custos. Revista Catarinense da Ciência Contábil, 19, 1-14.

Pant, I., \& Baroudi, B. (2008). Project management education: The human skills imperative. International journal of project management, 26(2), 124-128.

Peleias, I. R., Silva, G. P. D., Segreti, J. B., \& Chirotto, A. R. (2007). Evolução do ensino da contabilidade no Brasil: uma análise histórica. Revista Contabilidade \& Finanças, 18(spe), 19-32.

Peleias, I. R., \& Bacci, J. (2004). Pequena cronologia do desenvolvimento contábil no Brasil: Os primeiros pensadores, a padronização contábil e os congressos brasileiros de contabilidade. Revista Administração on line-FECAP, 5(3), 39-54.

Pereira, E. M., Niyama J. K., \& Freire, F. S. F. (2012, julho). Convergência das Normas Internacionais de Contabilidade: Uma análise a luz das teorias da educação de Paulo Freire e Libaneo nas instituições de ensino do Distrito Federal. Anais do Congresso USP de Controladoria e Contabilidade, São Paulo, SP, 12.

Perrenoud, P. (1999). Construir as competências desde a escola. Porto Alegre: Artes Médicas Sul.

Picard, C. F., Durocher, S., \& Gendron, Y. (2014). From meticulous professionals to superheroes of the business world. Accounting, Auditing \& Accountability Journal, 27(1), 73-118. 
Rhodes, N. (2015). Creating value in accounting education with a qualitative research methodology. Journal of Economic and Financial Sciences, 8(3), 728-741.

Rodrigues, L. L., Schmidt, P., \& Dos Santos, J. L. (2012). The origins of modern accounting in Brazil: Influences leading to the adoption of IFRS. Research in Accounting Regulation, 24(1), 15-24.

Rodrigues, L. L., \& Sangster, A. (2013). The role of the state in the development of accounting in the Portuguese-Brazilian Empire, 1750-1822. Accounting History Review, 23(2), 161184.

Russell-Wood, A. J. (2002). Slavery and freedom in colonial Brazil. Oxford: Oneworld.

Schmutte, J. (2005). Public accounting firm characteristics: their importance to students and discussion by recruiters. Journal of Applied Business Research (JABR), 21(1).

Scott, M. R., Tassin Jr., M. F., \& Posey, C. L. (1998). A discriminant analysis profile of the early development of professional accounting capabilities. Issues in Accounting Education, 13(2), 341-356.

Silva, G. B., \& Felicetti, V. L. (2014). Habilidades e competências na prática docente: perspectivas a partir de situações-problema. Educação por escrito, 5(1), 17-29.

Silva, M. A. (2015). De Portugal ao Brasil: a trajetória histórica do ensino superior de Contabilidade (1940-1985): concepções e tendências relativas aos aspectos de formação dos profissionais em contabilidade. (Tese de Doutorado). Faculdade de Educação, Universidade Federal de Uberlândia, Uberlândia, MG.

Smith, K. J., Haight, T. D., Emerson, D. J., Mauldin, S., \& Wood, B. G. (2020). Resilience as a coping strategy for reducing departure intentions of accounting students. Accounting Education, 29(1), 77-108.

Tan, L. M., \& Laswad, F. (2018). Professional skills required of accountants: what do job advertisements tell us?. Accounting Education, 27(4), 403-432.

Taylor, J. (1997). Introduction to error analysis, the study of uncertainties in physical measurements.

Thomson, J. (2017). Is the Accounting Profession Committed to Closing the Skills Gap?. The CPA Journal, 87(9), 16-17.

Vendramin, E. O., \& Araujo, A. M. P. (2020). A teoria da aprendizagem significativa e a estratégia de ensino método do caso: um estudo no ensino superior de contabilidade introdutória. Revista Gestão Universitária na América Latina-GUAL, 157-179.

Wilder, W. M., \& Stocks, M. H. (2004). Are accounting graduates favorably recruited for entrylevel management positions? A survey of recruiters of business school graduates finds empirical evidence to dispel the common misperceptions that a major in accounting limits students' career opportunities or the type of work they will perform in their jobs. Management Accounting Quarterly, 5(3), 21-28. 